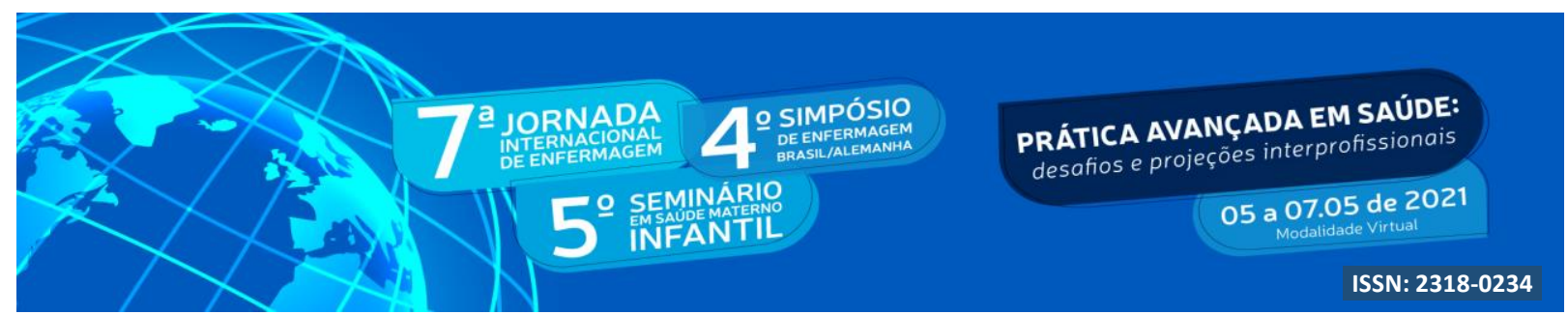

DOI: http://doi.org/10.48195/jie2021-031

\title{
SAÚDE, ENFERMAGEM, VIOLÊNCIA E O DESARMAMENTO ${ }^{1}$
}

\author{
Joice Cristina de Paula ${ }^{2}$; Edilene Aparecida Araújo da Silveira ${ }^{3}$; Selma Maria Fonseca \\ Viegas $^{4}$
}

\section{RESUMO}

Ao refletir sobre a importância do direito à saúde e como o exercício desta garantia interfere na vida dos profissionais e na saúde coletiva, comprendemos a relevância de diminuir a taxa de violência no país, em especial a provocada por arma de fogo. Objetivo: analisar a contribuição dos profissionais da saúde ao lidar com situações de violência provocada por arma de fogo. Método: trata-se de um ensaio teórico. Discussão: é notável a dificuldade em controlar a violência no Brasil, apesar de existir amparo legal que contribui para a redução, melhora da saúde coletiva e condições de trabalho, ocorre de modo falho. Conclusão: a efetiva redução da violência provocada por arma de fogo é interdependente do cumprimento da legislação e das políticas públicas de maneira concreta e alinhada com a realidade social.

Palavras-chave: Desarmamento; Enfermagem; Saúde; Violência.

\begin{abstract}
When reflecting on the importance of the right to health and how its guarantee interferes on the lives of professionals and collective health, we understand the relevance of reducing the violence rate in the country, especially that one caused by firearms. Objective: To analyze the contribution of health professionals in addressing firearm-related violence. Method: A theoretical essay. Discussion: It is notable the difficulty of controlling violence in Brazil, although there is legal support, which contributes to the reduction of violence, improvement of collective health and working conditions, it is in a flawed way. Conclusion: The effective reduction of firearm-related violence is interdependent on the concrete compliance of both legislation and public policies, aligned with the social reality.
\end{abstract}

Key Words: Disarmament; Nursing; Health; Violence.

\footnotetext{
${ }^{1}$ Mestrado. Universidade Federal de São João Del-Rei.

${ }^{2}$ Mestranda em Enfermagem. Universidade Federal de São João Del-Rei. E-mail:joicedipaula@hotmail.com

${ }^{3}$ Orientadora. Doutora. Universidade Federal de São João Del-Rei. E-mail:edileneap@ufsj.edu.br

${ }^{4}$ Coorientadora. Pós-Doutora. Universidade Federal de \$ão João Del-Rei. E-mail:selmaviegas@ufsj.edu.br
} 


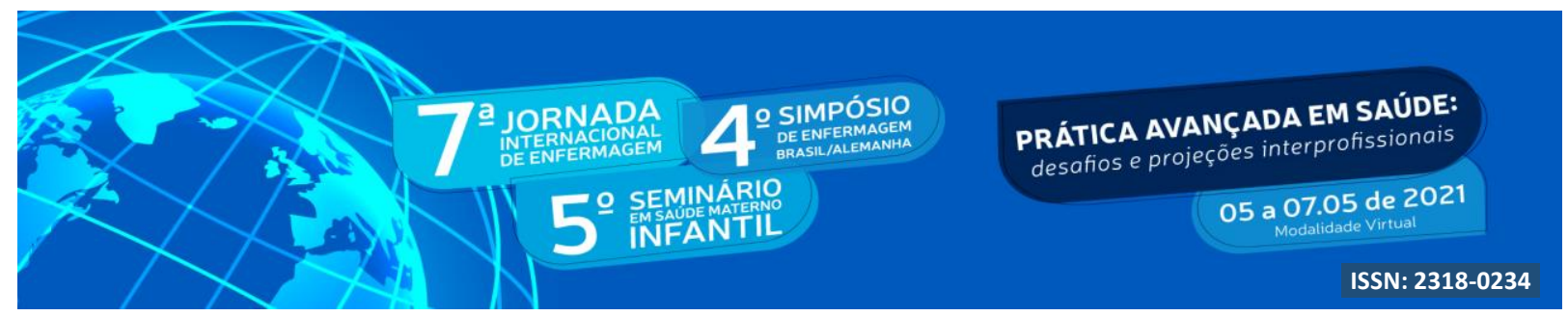

\section{INTRODUÇÃO}

A saúde, como direito essencial garantido por normas nacionais e internacionais, sofreu alterações no decorrer dos tempos para buscar melhorar as condições de vida para a população. Desde a confecção da Declaração Universal de Direitos Humanos pelas Nações Unidas, várias prerrogativas foram impostas diante de acontecimentos que confirmaram a fragilidade do sistema de saúde mundialmente. No Brasil, para ratificação das ideias trazidas por esta Declaração e por diversas parcerias internacionais estabelecidas, foi idealizada e promulgada a Constituição da República Federativa do Brasil de 1988, documento essencial para o desenvolvimento mais humanitário do país (BRASIL, 1988).

Vários questionamentos voltados ao direito à saúde, ao exercício digno desta prerrogativa e à influência que se tem ante aos anseios sociais foram feitos no decorrer do tempo. Muitos profissionais questionam a efetividade do exercício deste direito, como é o caso dos enfermeiros, essenciais para disponibilizar à população atenção à saúde de qualidade, de acordo com o que é ofertado pelo Estado, mas, muitas vezes, não conseguem devido a fatores externos. Alguns costumes sociais também podem influenciar no bom andamento dos processos de saúde, como o uso da arma de fogo, responsável por grande parte do aumento da violência em várias situações (MINAYO et al., 2018).

Nota-se a importância de atentar-se para realidade da saúde, pois esta não se limita apenas ao que é legalmente disposto, ao que é executado e ao que é visto a olhos nus, mas também observar como os profissionais lidam com a própria saúde e a de terceiros em casos de violência envolvendo arma de fogo (PIRES et al., 2016).

\section{OBJETIVO}

Refletir sobre a contribuição dos profissionais da enfermagem para a saúde coletiva na atenção em casos de violência e a importância das políticas de desarmamento para o bemestar da população. 


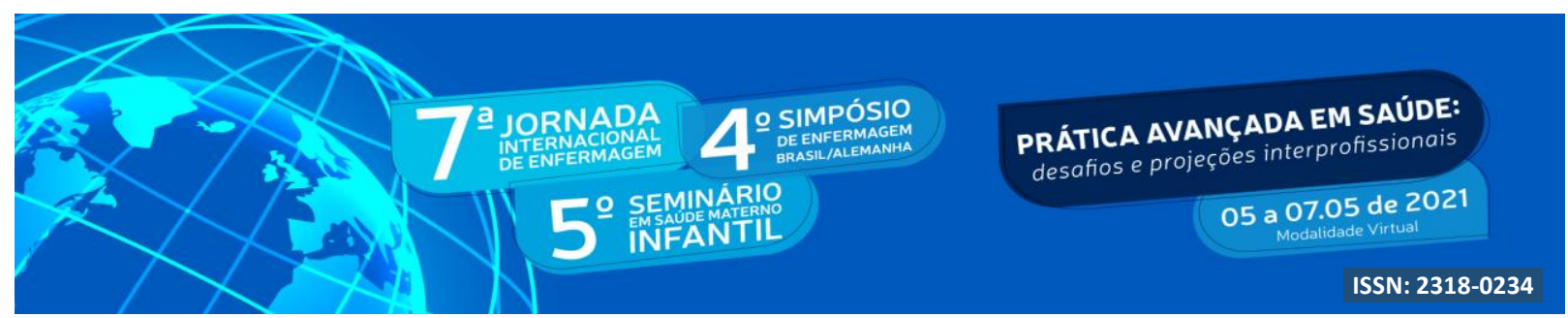

\section{METODOLOGIA}

Trata-se de Ensaio Teórico ancorando reflexões sobre a saúde e a influência da redução da violência armada. O Ensaio Teórico instiga à reflexão do leitor para proporcionar formação de opiniões essenciais para a evolução do conhecimento.

O ensaio é um instrumento de avaliação de determinado objeto em estudo, por meio do estado da arte, atentando para a realidade de maneira não radical, mas problematizadora e considerando a subjetividade. Neste trabalho é baseado na revisão da literatura e analisa a importância de políticas públicas e legislações para controle armamentista e a influência da violência armada na atuação dos enfermeiros (MENEGHETT, 2011).

A discussão se fundamentará nas bases legislativas, como na Declaração Universal de Direitos Humanos de 1948, na Constituição da República Federativa do Brasil de 1988, na Lei no 8080 de 1990 e na Lei no 10.826 de 2003.

\section{RESULTADOS E DISCUSSÃO}

O contexto histórico de evolução da saúde vem há muito tempo sendo preocupação dos poderes públicos de todas as nações, especialmente diante do contexto pandêmico atual pelo qual estamos passando. A Declaração Universal de Direitos Humanos de 1948 trouxe valores importantes para o desenvolvimento social, quando observa a importância dos direitos fundamentais, da dignidade e do valor do ser humano em todos os contextos. Esta Declaração, no artigo 25, enfatiza a necessidade de todo cidadão ter direito à saúde:

\footnotetext{
"Todo ser humano tem direito a um padrão de vida capaz de assegurar a si e à sua família saúde, bem-estar, inclusive alimentação, vestuário, habitação, cuidados médicos e os serviços sociais indispensáveis e direito à segurança em caso de desemprego, doença invalidez, viuvez, velhice ou outros casos de perda dos meios de subsistência em circunstâncias fora de seu controle (PARIS, 1948)."
}

Para os países que aceitaram esta Carta para aplicabilidade interna, como é o caso do Brasil, tem que se fazer cumprir o que nela está descrito, principalmente no que se refere à vida digna, tópico sempre reafirmado pela Declaração. O Brasil, como forma de implantar o convencionado na Declaração Universal de Direitos Humanos, posterior a muitas mudanças políticas no país, promulgou a Constituição da República Federativa do Brasil de 1998, reafirmando os direitos presentes na Declaração Universal e estabeleceu novas prerrogativas. 


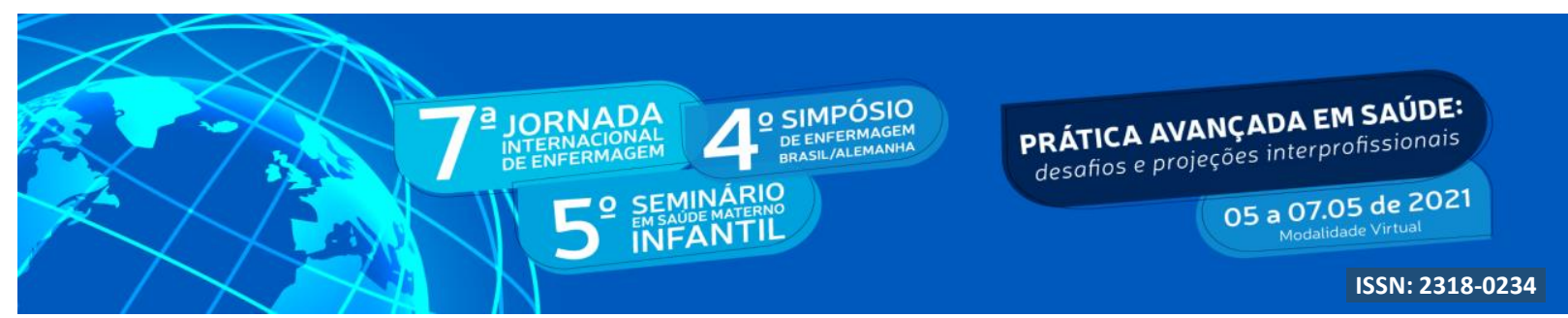

Foi um importante marco para o país, especialmente por ter como fundamento inicial o princípio da dignidade da pessoa humana (BRASIL, 1988).

Assim vieram os direitos sociais, entre eles à saúde, educação, trabalho, moradia, entre outros essenciais para a população. Dispor sobre o direito à saúde envolve inúmeros fatores, tanto que a Constituição trouxe uma seção específica para tratar sobre o assunto. Expõe que a saúde deve ser garantida a todos e é dever do Estado fazer com que isso se cumpra, por meio de políticas sociais e econômicas que promovam a redução do risco de doenças graves para a população, inclusive disponibilizando tratamentos gratuitos (BRASIL, 1988).

Após a aprovação da Constituição de 1988 pela Assembleia Constituinte, que institui o Sistema Único de Saúde (SUS) como sistema público de acesso universal, integral e equânime, foi aprovada a Lei 8080 em 1990, que dispõe sobre as condições para a promoção, proteção e recuperação da saúde, a organização e o funcionamento dos serviços correspondentes, entre outras condições. Esta lei é muito importante para o desenvolvimento sanitário do país, pois trouxe diversas garantias para o acesso universal da população, incluindo pessoas/famílias que não detinham de atenção à saúde, pela expansão da Atenção Primária à Saúde (APS) em todo território brasileiro, reduzindo as disparidades sociais e regionais existentes pela extensão geográfica continental do país e proporcionando condições melhores para todos (BRASIL, 1990; NASCIMENTO et al., 2020). O SUS foi interpretado como um conjunto de atividades e serviços desempenhados por órgãos e instituições públicas federais, estaduais e municipais, pela administração pública (BRASIL, 1990).

É necessária maior visibilidade e valorização dos profissinais da saúde, pois estes vivenciam diversos desafios no cotidiano de trabalho, não é apenas pela abordagem técnica/teórica das ações e procedimentos, mas pela responsabilização sanitária, pela sensibilidade do olhar crítico considerando as singularidades dos sujeitos e situações, para tomada de decisões e boas práticas e seguras, isto alinhado aos preceitos éticos, políticos e sociais que devem ser obedecidos em suas funções/ações. Exercer funções no setor da saúde é desenvolver trabalho essencial para a vida, faz diferença na evolução do mundo, das pessoas e na redução de acontecimentos fatais, violentos, que comprometam a vida digna (VIEGAS, 


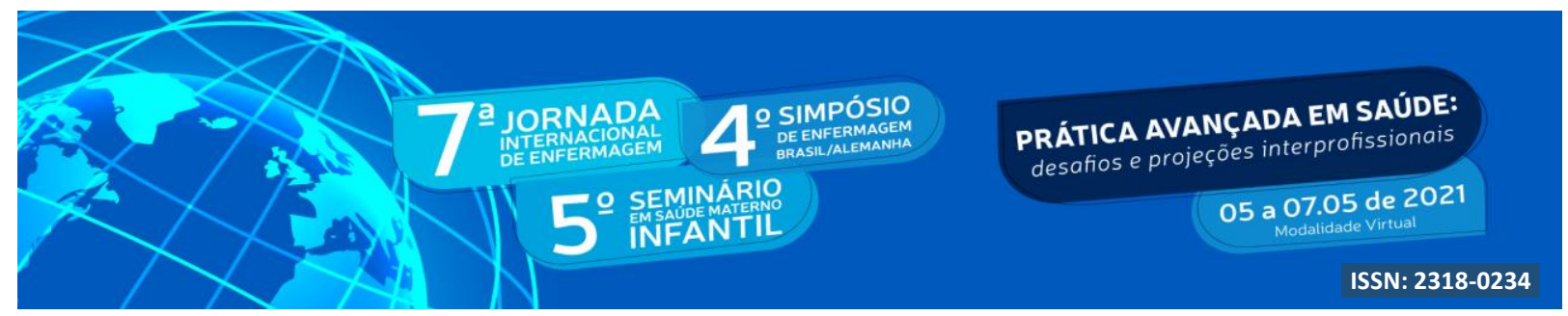

2020; PIRES, et al., 2016).

A inserção da temática violência no contexto do SUS teve impacto maior com a implangação da Política Nacional de Redução da Morbimortalidade por Acidentes e Violência, que objetivou orientar a atuação do setor da saúde e reconhecer a violência como assunto de grande impacto público. Levou em consideração a necessidade de implantação de políticas decisivas para redução da mortalidade, responsabiliza e institui diretrizes para todos os setores envolvidos com o Ministério da Saúde. O documento reconhece a amplitude do fenômeno nas bases sociais, políticas e econômicas da população, bem como as relações individuais que geram conflitos (BRASIL, 2001)

Perante toda evolução no contexto de saúde vivenciado pelos cidadãos, algumas questões surgem para mostrar certas falhas e influências no bom desenvolvimento do sistema de saúde, como é o caso da violência provocada por arma de fogo, assunto de grande impacto que permeia à saúde coletiva. O Brasil é um país com grandes taxas de homicidios provocado por arma de fogo, só em 2017 foram 65,6 mil mortes violêntas, sendo que 74,4\% foram provocadas por arma de fogo. São inúmeras as razões que favorecem o aumento das taxas de mortalidade por esta causa, entre eles a urbanização, a criminalidade e o acesso facilitado (QUEIROZ, 2019).

É dificil que não existam conflitos sociais em uma comunidade, ocorre que o aumento da violência gera mortes, traumas físicos, traumas psicológicos, lesões, impacta diretamenta no cotidiano das pessoas, gera novos atendimentos hospitalares e aumenta a demanda nas unidades de saúde. Nota-se que há necessidade de atuação para tratamento e prevenção do problema, responsabilidade do Estado e da comunidade, pois refere-se a algo emergente. Estes fatores denotam a evolução da intersetorialidade e interdisciplinariedade dos setores, não só de saúde, mas o jurídico, social, político, que devem especial cuidado com a temática, pricipalmente no que se refere à violência com arma de fogo (MINAYO, et al, 2018).

Conforme os dados apresentam, é necessário o controle armamentista no Brasil, fato inclusive amplamente tratado quando foi aprovado o Estatuto do Desarmamento, Lei 10.826 de 2003, que veio na intenção de reduzir a posse e o porte de arma pelos cidadãos e tornar mais rigorosa a fiscalização. Uma consulta popular sobre a proibição de comercialização de 


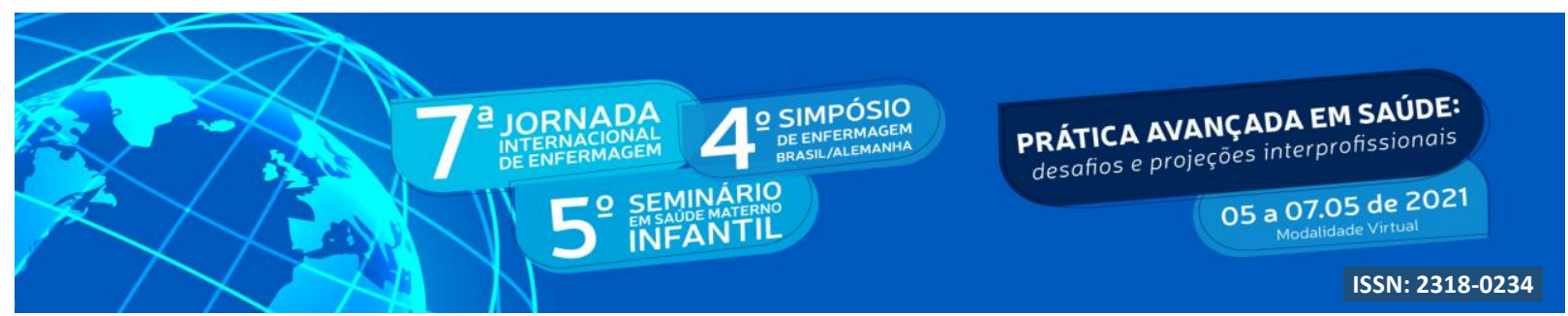

arma de fogo aconteceu por um referendo, em 2005, no qual foi decidido que não deveria ser proibida. Houve também a Campanha do Desarmamento que incentivou àqueles que possuíam arma de fogo irregular que às entregassem, sem sanção e com indenização à polícia, num prazo estabelecido, possibilitando a entrega de muitas armas (BRASIL, 2003).

A Constituição Federal de 1988 afirma, em seu art. 144, que a segurança pública é dever do Estado e, também, direito e responsabilidade de todos, com a finalidade de preservação da ordem pública. Observa-se que o Estatuto do Desarmamento tem o propósito político de afirmar o prescrito constitucionalmente de maneira legislativa, foi estabelecida uma norma juntamente com políticas públicas. A lei propõe reduzir os dilemas que envolvem a posse e o porte de arma de fogo, bem como, a produção e comercialização para reduzir a criminalidade e a mortalidade facilitadas por este meio tão letal (HIEDA, 2014).

Percebe-se o impacto na saúde pública que o armamento tem, como a necessidade de políticas efetivas para o controle. A violência é tema de muitos debates que envolvem o cuidado e interfere diretamente nos trabalhos dos profissionais da enfermagem e no contexto social, muitas causas de internações hospitalares ocorrem devido à acidentes e homicídios. Isto evidencia a importância do papel dos profissionais da saúde na luta contra a violência, ressalta a junção de competência e engloba aspectos jurídicos e sociais (SOUZA et al., 2020).

O enfermeiro exerce a função de direção e liderança ao receber pacientes vítimas de violência em centros de saúde, atuando como mediador ao realizar o atendimento. $\mathrm{O}$ profissional pode ser afetado, tem o risco de sua integridade física, o que pode ocasionar redução no desempenho das funções de impacto na saúde física e mental. O cotidiano de trabalho é pesado, envolve relações interpessoais e lidar com pacientes vítimas de violência armada pode gerar apreensão e desconforto (FLORIDO et al., 2020).

A violência impacta no desempenho da saúde, muitas das vezes impondo limitações ao acesso da população em determinadas áreas, como naquelas que são comum conflitos armados. Os profissionais da saúde em determinadas situações se veem expostos à violência, às vezes por trabalharem em locais mais vulneráveis, com índice mais alto de criminalidade. Isto demanda do enfermeiro o desenvolvimento de técnicas para se adaptar à realidade exposta, pois se depara com insegurança e medo ao desenvolver suas funções (SANTOS; SILVA; BRANCO, 2017). 


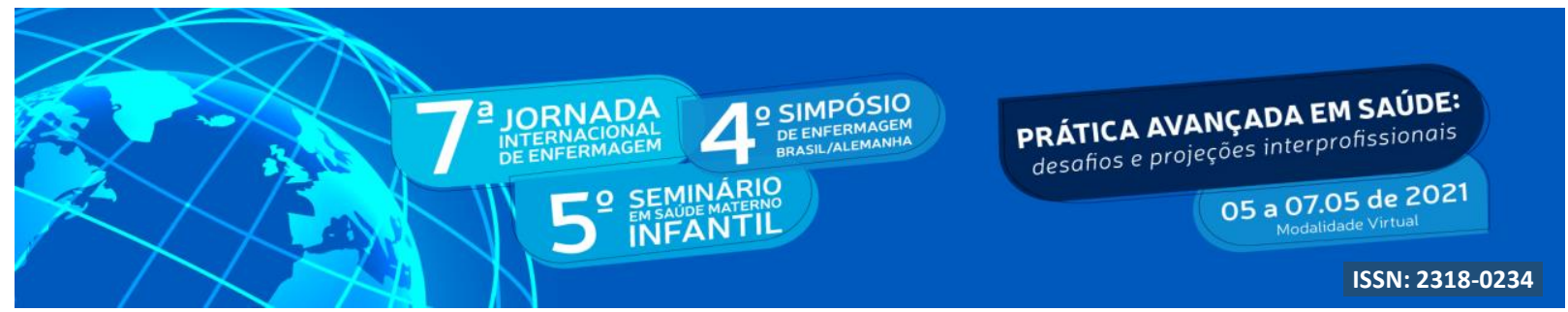

A falha na implementação de políticas envolve situações de vários âmbitos. Ocorre que existem políticas públicas, como o Estatuto do Desarmamento, para dirimir este tipo de conflito, tem-se obrigações estatais, como a preservação da vida dos indivíduos e a segurança pública, porém há lacunas na execução da legislação e na efetivação dos serviços, muitas vezes, faltam profissionais ou àqueles envolvidos não conseguem solucionar a situação por ausência de preparo ou condições de trabalho. Considera-se que as esferas jurídicas, da saúde e assistência social possuem obstáculos para trabalharem juntas na prevenção da violência, especialmente em se tratando dos grupos mais vulneráveis, mulheres, crianças, homossexuais, travestis, idosos, indígenas, entre outros (SOUZA, et al., 2020).

\section{CONCLUSÃO}

Para o combate à violência e sua redução, ainda tem muito o que ser feito incluindo a efetivação do que é estabelecido legalmente. A promulgação da Constituição Federal de 1988, da Lei 8080/1990 e do Estatuto do Desarmamento, foram grandes marcos políticos que trouxeram garantias para a população em geral. Ocorre que há necessidade de ação conjunta de vários setores para resolver questões relacionadas à violência, muito se foi alcançado, mas os desafios persistem. Pelo dados epidemiológicos que registram o aumento da violência em todo o mundo e no Brasil, esta é uma temática que deve ter prioridade pelos governates devido ao impacto na saúde coletiva.

A implantação ou fortalecimento de políticas mais eficazes melhoraria o desenvolvimento da saúde no país, tanto no que se refere aos usuários quanto em relação aos enfermeiros. Uma ideia seria tornar mais efetiva a atuação política educacional e melhora das normas de atendimentos às vítimas e mecanismos que facilitem a redução da violência. Os enfermeiros ao exercerem suas funções vivem situações difíceis relativas ao receio de desempenhar a profissão, de tomar alguma atitude errada ao lidar com situações de emergência e até mesmo o temor pela integridade física (SOUZA, et al., 2020).

Deste modo, resta claro o impacto do desarmamento no bom andamento da saúde pública, tanto na redução da mortalidade como no desempenho das funções dos profissionais envolvidos. 


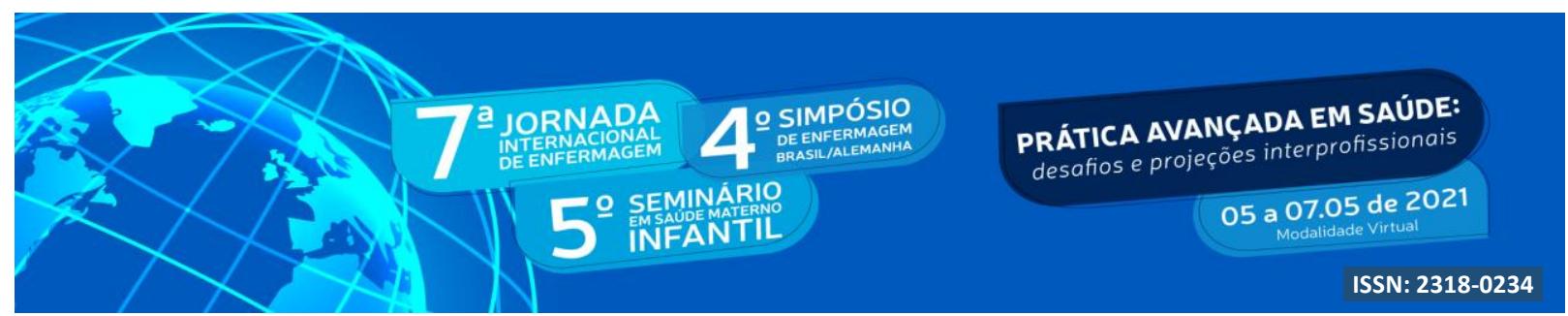

Apoio governamental e políticas públicas que viabilizem a atuação dos profissinais na execução do trabalho, melhora de condições e colaboração social são aspectos que influenciariam positivamente na segurança pública.

Portanto, constata-se a relevência de se ter ações coletivas para alcançar a finalidade de reduzir a violência em sua base, sem que grandes prejuízos sejam necessários para chamar a atenção do poder público e prezar por uma vida digna, saudável e segura.

\section{REFERÊNCIAS}

BRASIL. Constituição da República Federativa do Brasil de 1988. Brasília, DF: Presidência da República. Brasília, DF, 1988. Acesso em: 15 Fev 2021. Disponível em: http://www.planalto.gov.br/ccivil_03/constituicao/constituicao.htm

BRASIL. Lei 8080 de 1990. Dispõe sobre as condições para a promoção, proteção e recuperação da saúde, a organização e o funcionamento dos serviços correspondentes e dá outras providências. Brasília, DF, 1990. Acesso em: 15 Fev 2021. Disponível em: http://www.planalto.gov.br/ccivil_03/leis/18080.htm.

BRASIL. Estatuto do Desarmamento. Lei 10.826 de 22 de dezembro de 2003. Brasília, DF, 2003. Disponível em: http://www.planalto.gov.br/ccivil_03/Leis/2003/L10.826compilado.htm

BRASIL. Ministério da Saúde. Portaria No 737, DE 16 DE MAIO DE 2001. Aprova a Política Nacional de Redução da Morbimortalidade por Acidentes e Violências. Brasília, DF, 2001. Acesso em: 25 Fev 2021. Disponível em: http://bvsms.saude.gov.br/bvs/publicacoes/politica_reducao_morbimortalidade_acidentes_2ed .pdf

BRASIL. Lei 7.498, de 25 de junho de 1986. Dispõe sobre a regulamentação do exercício da enfermagem e dá outras providências. BRASÍLIA: Ministério Da Saúde; 1986. [Citado em 05 Maio 2008]. Disponível em: http://www2.camara.gov.br/internet/legislacao/legin.htm.

FLÓRIDO, Helena Guimarães; DUARTE, Sabrina da Costa Machado; FLORESTA, Waleska Menengat Corrêa; MARINS, Aline Miranda da Fonseca; BROCA, Priscilla Valladares; MORAES, Juliana Rezende Montenegro Medeiros de. Gerenciamento das situações de violência no trabalho na estratégia de saúde da família pelo enfermeiro. Texto \& Contexto Enfermagem 2020, v.29:e20180432. DOI http://dx.doi.org/10.1590/1980-265X-TCE-20180432 


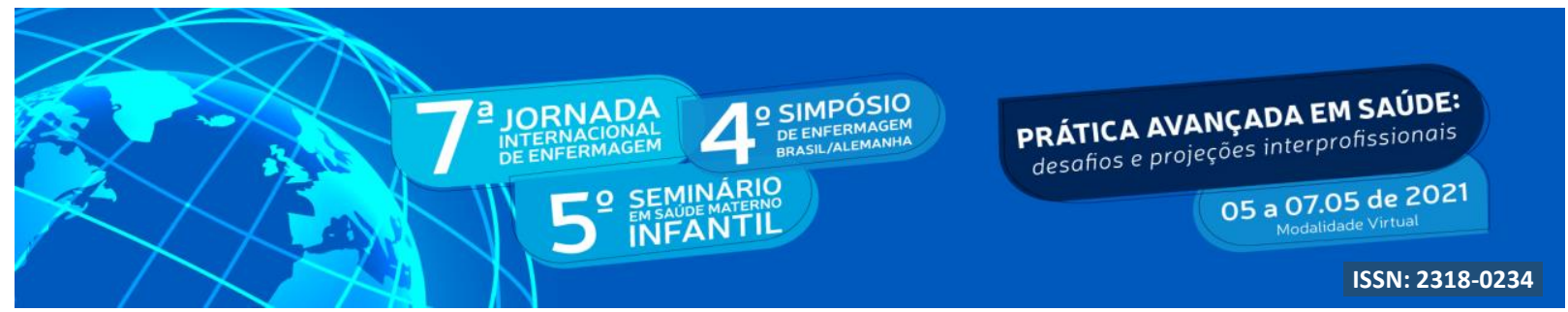

HIEDA, Erik Keiti. Impacto do Estatuto do Desarmamento em saúde pública: Uma análise de indicadores de mortalidade e morbidade por causas externas no estado de São Paulo. Universidade de São Paulo Escola de Artes, Ciências e HumanidadeS, São Paulo, 2014. Acesso em: 20 Fev 2021. Disponível em: http://each.uspnet.usp.br/flamori/images/TCC_Erik_2014.pdf

MENEGHETTI, Francis Kanashiro. O que é ensaio teórico? RAC, Curitiba, v. 15, n. 2. Pag. 320-332, Mar/Abr, 2011. Acesso em: 10 mar 2021. Disponível em: http://www.anpad.org.br/rac

MINAYO; Maria Cecilia de Souza; SOUZA, Edinilsa Ramos de; SILVA, Marta Maria Alves da; ASSIS, Simone Gonçalves de. Institucionalização do tema da violência no SUS: avanços e desafios. Ciência \& Saúde Coletiva, 23(6):2007-2016, 2018. DOI: 10.1590/141381232018236.04962018

NASCIMENTO, L. C.; VIEGAS, S. M. F.; MENEZES, C.; ROQUINI, G. R.; SANTOS, T. R. O SUS na vida dos brasileiros: assistência, acessibilidade e equidade no cotidiano de usuários da Atenção Primária à Saúde. Physis, v. 30, n. 3, e300330, 2020. DOI: https://doi.org/10.1590/s0103-73312020300330.

PARIS. Assembleia Geral da ONU. "Declaração Universal dos Direitos Humanos". 217 (III) A. Paris, 1948. Acesso em: 20 Fev 2021. Disponível em: https://www.unicef.org/brazil/declaracao-universal-dos-direitos-humanos.

PIRES, Denise Elvira Pires de; AMADIGI, Felipa Rafaela; ALBUQUERQUE, Luiz de; ALBUQUERQUE, Gelson Luiz de. Enfermagem: desafios em um contexto complexo. $1^{\mathrm{a}}$ Conferência de Enfermagem do Estado de Santa Catarina. Cofen, Florianópolis, SC, 2016. Acesso em: 20 Fev 2021. Disponível em: http://www.corensc.gov.br/wpcontent/uploads/2016/08/texto-norteador_.pdf

QUEIROZ, Christina. Desarmando a violência. Revista Pesquisa Fapesp, Humanidades saúde pública, edição 281, 2019. Acesso em: 22 Fev 2021. Disponível em: https://revistapesquisa.fapesp.br/desarmando-a-violencia/

SANTOS, Milena da Silva; SILVA, Juliana Guimarães e; BRANCO, July Grassiely de Oliveira. O enfrentamento à violência no âmbito da estratégia saúde da família: desafios para a atenção em saúde. Revista Brasileira em Promoção da Saúde, vol. 30, núm. 2, abril-junio, 2017, pp. 229-238. DOI: 10.5020/18061230.2017

SOUZA, Jhuliano Silva Ramos de; VILELA, Sueli de Carvalho; COSTA, Andreia Cristina Barbosa; SILVA, Sinézio Inácio da. Política, segurança e saúde pública no brasil: combatendo a violência. Rev enferm UFPE on line. 2020;14:e244226. Acesso em: 02 fev 2021. Disponível em: https://periodicos.ufpe.br/revist as/revistaenfermagem doi: 10.5205/1981-8963.2020.244226. 


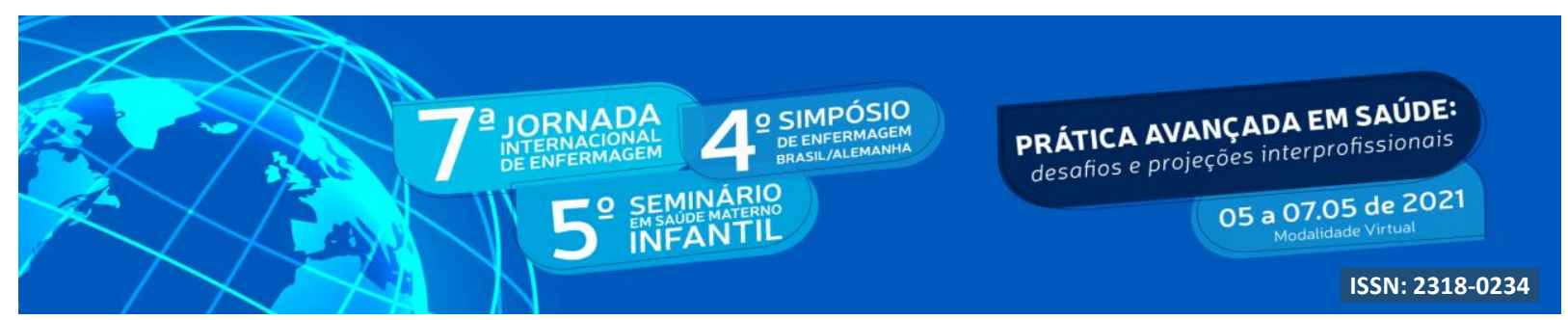

VIEGAS, S. M. F. Lâmpada que não se apaga: enfermagem em prol do reconhecimento social e valorização de seus profissionais. HU Rev. [S. 1.], v. 46, p. 1-2, 2020. DOI: 10.34019/19828047.2020.v46.32774 